\title{
Editor's thanks and farewell
}

\author{
$\sim$ labor ipse voluptas
}

This issue of Canadian Studies in Population marks the end of my tenure as its Editor-in-Chief. During the past eleven years I have built on the important work of my predecessors, Professors Wayne McVey, Jr., Herbert Northcott, George Jarvis, and Parameswara Krishnan. I am honoured to be part of this group of esteemed scholars and to have had the opportunity to serve the community of population scientists in my capacity as Editor.

Over the course of my editorship I have guided Studies through a number of important developments. Early after stepping into the editorial office in 2008, I secured entry of the journal into the Directory of Open Access Journals (DOAJ), which made it possible for anyone in the world with an internet connection to access it for free. Shortly after, we ceased issuing printed copies. From this change, we lost a subscription base; however, we were successful in gaining funding from the Social Sciences and Humanities Research Council of Canada (SSHRC) over successive Aid for Scholarly Journals competitions. The SSHRC funding greatly facilitated our ability to produce and publish Studies on a biannual basis. In 2012, following a rigorous evaluation process, Canadian Studies in Population was accepted into the Web of Science citation indexing service, and also indexed in Current Contents/Social and Behavioral Sciences, the Social Sciences Citation Index, and Sociological Abstracts. More recently, in co-operation with the University of Alberta Libraries' Digital Initiatives team, DOI registration was added to all current and archived contents of the CSP website on the Open Journal System (OJS) platform. These developments, among others, have helped to enhance the journal's international visibility and reputation. According to the Scopus Scimago Journal \& Country Rank index, since 2012 Canadian Studies in Population has been ranked in the top ten open-access demography journals worldwide, with a high mark of fourth place in 2016.

Many individuals have contributed to make Canadian Studies in Population an important scholarly outlet. With their help and cooperation I have had the privilege of spearheading the production and publication of 21 issues of Studies, encompassing over 170 articles or special essays/reviews and involving the participation of more than 350 Canadian and international authors.* The intellectual legacy of the journal lives on through the important contributions of these scholars.

I am especially grateful to all those who gave their expertise to review manuscripts and books received for publication. I also thank the members of the Editorial Board for their service and wise counsel, SSHRC Canada for its support, and the Department

\footnotetext{
* These numbers do not include nine scholarly articles that were submitted to CSP and accepted for publication after successfully passing the peer review process.
} 
of Sociology at the University of Alberta for having hosted the journal since its inception in 1974. The OJS team at University of Alberta Libraries has been instrumental in providing expert technical facilitation of the CSP website and open access archive; I have been assured that this will continue for all back issues of Studies, including the present one. The Canadian Population Society is thanked for its collegial support. I am indebted to Ksenia Maryniak for her professionalism and dedicated assistance with the organization, production, and publication of Canadian Studies in Population. Last but not least, I extend my heartfelt appreciation to all the readers of Studies for their interest and sustained encouragement.

Frank Trovato

Editor-in-Chief

23 August 2018 